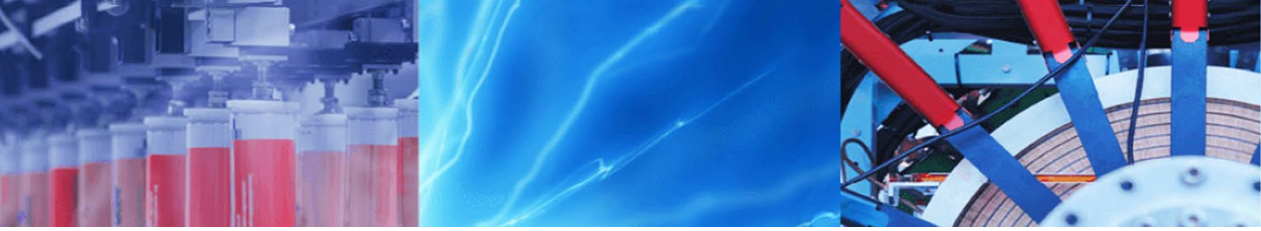

Short communication

\title{
Influence of rolling temperature and cooling rate on nano-size carbides in a Ti-Mo microalloyed steel
}

\author{
Hailong $\mathrm{Yi}^{1}$ (1) $\cdot$ Luran Zhang ${ }^{1} \cdot$ Zikun Yang $^{1}$
}

(c) Springer Nature Switzerland AG 2018

\begin{abstract}
Carbide precipitation in Ti-Mo ferrite-containing low carbon steel was investigated by hardness testing and transmission electron microscopy. Both the rolling temperature and cooling rate after holding affect the hardness of ferrite, and prolonged holding caused the small carbides to coarsen and aggregate, so that the hardness of ferrite decreased rapidly. The same hardness, however, was obtained at a slow cooling rate even after the same prolonged holding. Rolling in the recrystallization region created a precipitation-free zone near both the grain boundary and grain interior, and the low hardness of ferrite may be caused by low carbide density in ferrite due to precipitation-free zone near the grain boundary and within grains after short and prolonged holding times, and coarsening of carbides after prolonged holding times.
\end{abstract}

Keywords Particles · Nanosize · Grain boundaries · Rolling temperature $\cdot$ Cooling rate

\section{Introduction}

The excellent properties of Ti-Mo microalloyed steels recently became widely recognized, as both a tensile strength of $780 \mathrm{MPa}$ and a hole expansion ratio of $120 \%$ were obtained by precipitation strengthening which can reach approximately $300 \mathrm{MPa}$ without reducing the ductility [1]. Numerous studies focused on controlling nanoprecipitation coupling of $\mathrm{Ti}, \mathrm{Nb}, \mathrm{V}$, and Mo with two or three elements, and many precipitation mechanisms have been proposed to explain these strengthening effects [2-8]. However, most of these studies concentrated on changes in interphase precipitation characteristics with respect to chemical composition and isothermal phase transformation conditions. But the deformation process significantly affected the precipitation characteristics, and this behavior could directly influence the mechanical properties of steels [9-12]. Since the rolling temperature can affect the austenite grain boundaries, which function as nucleation sites for ferrite transformation via dynamic and/or non-dynamic recrystallization, the characteristics of nano-sized precipitation with respect to ferrite transformation should be closely related to the rolling temperature. In addition, the cooling rate after isothermal holding in ferrite transformation regions can affect interphase or random precipitation; for example, continuous interphase precipitation is expected if ferrite transformation is incomplete, or supersaturation precipitation can occur due to incomplete precipitation after isothermal holding $[13,14]$. To our knowledge, there is currently no consensus on this process due to its complexity.

Thus, the present study aims to investigate nano-sized carbide in ferrite after exposure to different rolling temperatures and cooling processes, and the influence of the rolling temperature and cooling rate after holding on carbide was discussed based on transmission electron microscopy and hardness results.

Hailong Yi, yihailong2015@163.com | The State Key Laboratory of Rolling and Automation, Northeastern University, Shenyang 110819, China. 


\section{Materials and methods}

The chemical composition of the investigated steel was Fe-0.08C-1.58Mn-0.24Si-0.11Ti-0.28Mo-0.005P0.002S-0.004 N (mass \%). Cylindrical samples of diameter $8 \mathrm{~mm}$ and height $15 \mathrm{~mm}$ were prepared, and the experiments were conducted using a Gleeble 3800 thermal simulator. The samples were heated to $1200^{\circ} \mathrm{C}$ at $10^{\circ} \mathrm{C} \mathrm{s}^{-1}$ and held for $300 \mathrm{~s}$, and then cooled from $1200{ }^{\circ} \mathrm{C}$ to $900{ }^{\circ} \mathrm{C}$ or $1,100^{\circ} \mathrm{C}$, at a rate of $10^{\circ} \mathrm{C} \mathrm{s}^{-1}$, and then deformed by $40 \%$ at a strain rate of $1 \mathrm{~s}^{-1}$ at this temperature. The specimens were then cooled at $10^{\circ} \mathrm{C} \mathrm{s}^{-1}$ to $700{ }^{\circ} \mathrm{C}$, and held isothermally for 60,600 , and $1800 \mathrm{~s}$, before cooling to ambient temperature at $0.1^{\circ} \mathrm{C} \mathrm{s}^{-1}$ and $50^{\circ} \mathrm{C} \mathrm{s}^{-1}$.

In order to describe the austenitic state after deformation accurately, the stress-strain curves deformed by $60 \%$ at a strain rate of $1 \mathrm{~s}^{-1}$ at $1100{ }^{\circ} \mathrm{C}$ and $900{ }^{\circ} \mathrm{C}$ were obtained, and the quenching microstructures after deformed by $40 \%$ at a strain rate of $1 \mathrm{~s}^{-1}$ at these two temperature were corroded using saturated picric acid aqueous solution at $70^{\circ} \mathrm{C}$, which were then observed using a Leica DM IRM optical microscopy. Microhardness of ferrite were taken using a FM-700 with a load of $10 \mathrm{~g}$, and the results are averages of 50 randomly selected ferrite grains. The carbon extraction replica and thin foil methods were used to identify the morphology and size distribution of the precipitates, and the samples were observed using field emission TEM (FEI Tecnai G2 F20) operating at $200 \mathrm{kV}$.

\section{Results and discussion}

Figure $1 \mathrm{a}$ shows the stress-strain curves of the steel deformed at $1100^{\circ} \mathrm{C}$ and $900^{\circ} \mathrm{C}$. The steel exhibited a typical dynamic recrystallization behavior only at $1100^{\circ} \mathrm{C}$, and the critical strain $\left(\varepsilon_{\mathrm{c}}\right)$ and peak strain $\left(\varepsilon_{\mathrm{p}}\right)$ were obtained as $\varepsilon_{\mathrm{c}}=0.2078$ and $\varepsilon_{\mathrm{p}}=0.4543$, respectively, using the method described detailed in the previous papers $[15,16]$. The quenching microstructures after deformed by $40 \%$ were
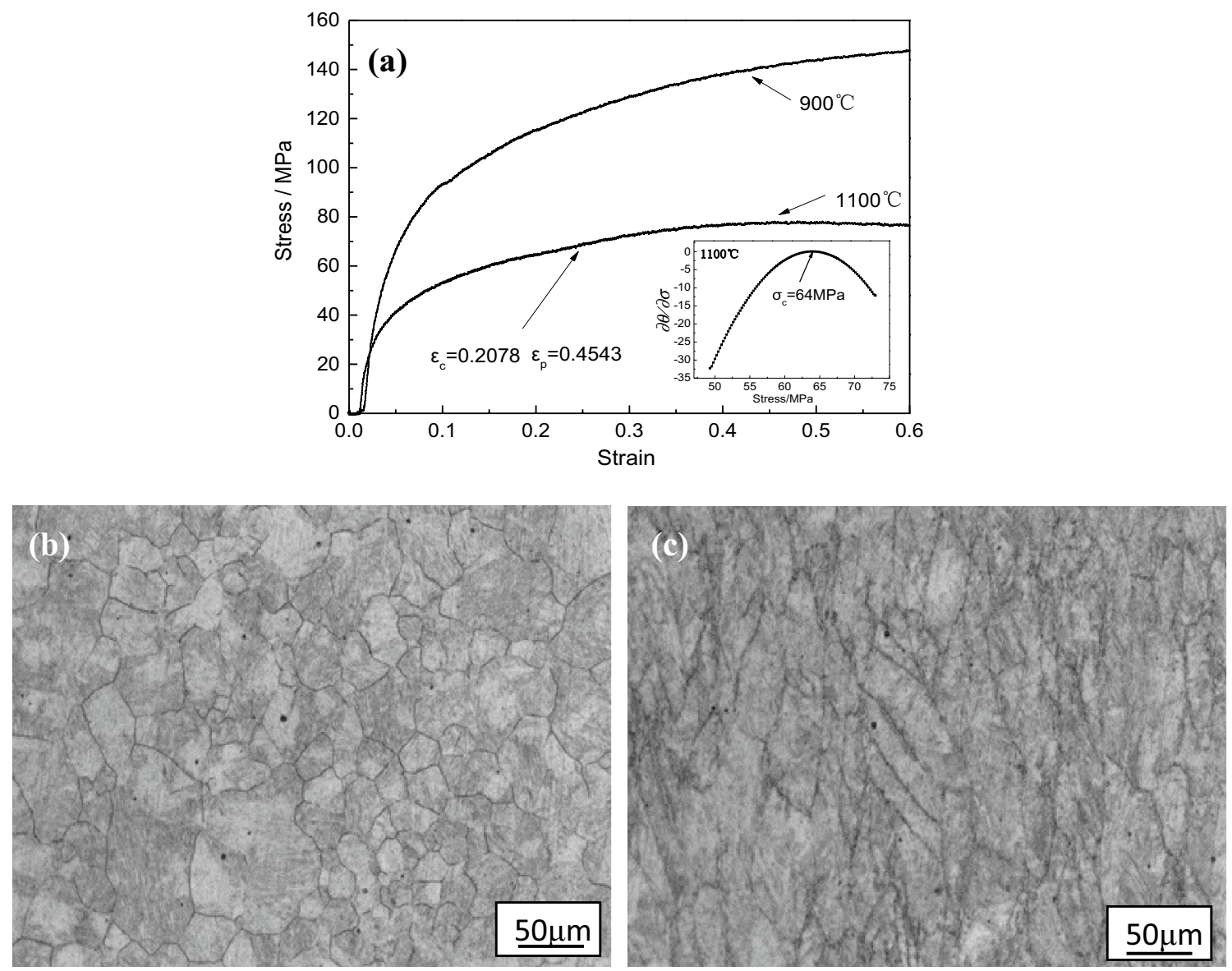

Fig. 1 The stress-strain curves (a) and quenching microstructures showing austenite morphologies after deformed at $40 \%$ at b $1100^{\circ}, \mathbf{c} 900^{\circ}$ 
shown in Fig. 1b, c, in which the equiaxed recrystallization and pancake non-recrystallization structures were observed for the rolling temperatures of $1100{ }^{\circ} \mathrm{C}$ and $900{ }^{\circ} \mathrm{C}$, respectively. For rolling in the austenite recrystallization region, rolling deformation can be accommodated by austenite recrystallization, which hinders dislocation accumulation. Conversely, deformation will cause significant dislocation accumulation when conducted in a nonrecrystallization region.

With respect to indirectly describing the amount of precipitation strengthening in the grain interior of ferrite, the hardness measurements were proved to be correct and already used widely [17-20]. The microhardness curves of steel for ferrite alone at different rolling temperatures and cooling rates after holding are shown in Fig. 2. The

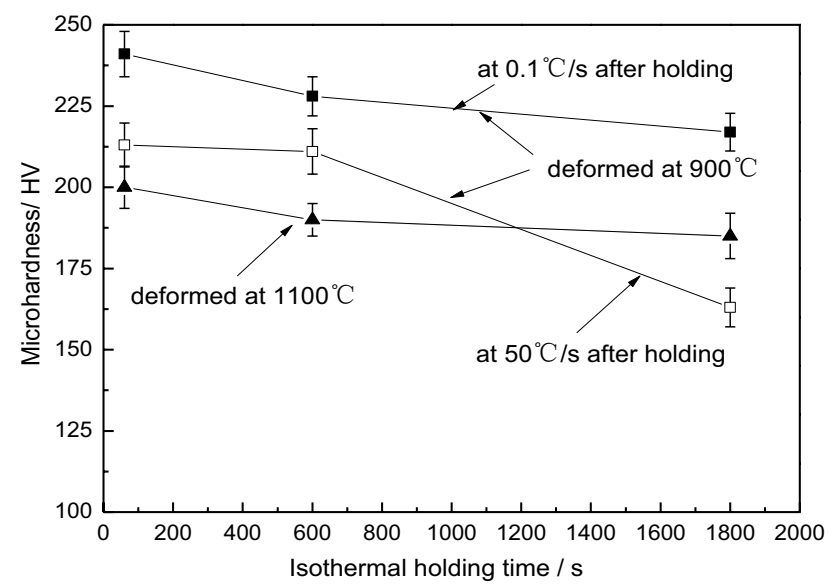

Fig. 2 Micro-hardness in ferrite with isothermal holding time at different processes

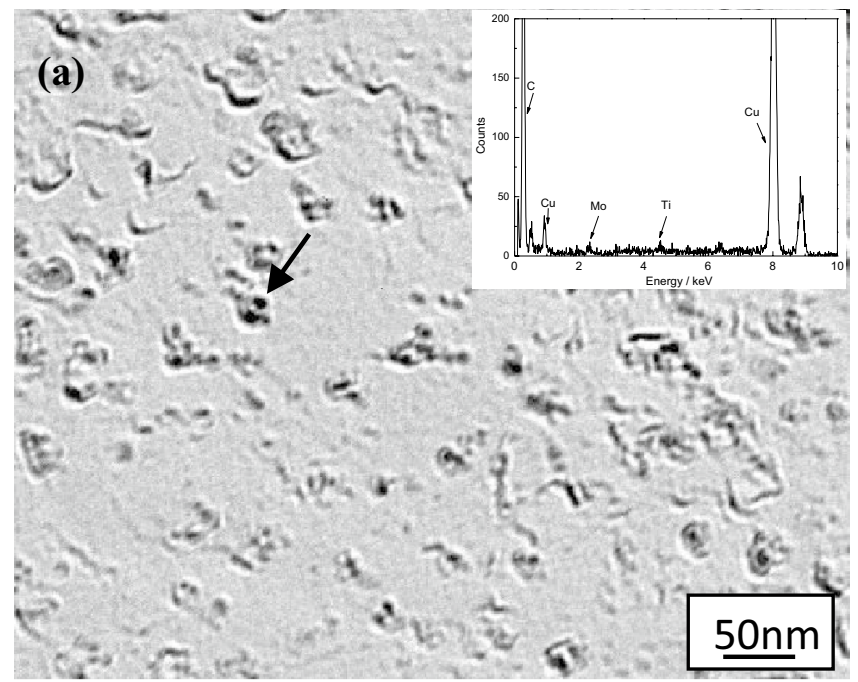

highest hardness was obtained at a cooling rate of $0.1^{\circ} \mathrm{C}$ $\mathrm{s}^{-1}$ after holding for $60 \mathrm{~s}$ and deforming at $900^{\circ} \mathrm{C}$, and the lowest hardness was obtained at a cooling rate of $50^{\circ} \mathrm{C} \mathrm{s}^{-1}$ after holding for $1800 \mathrm{~s}$ at the same deformation temperature. Overall, the hardness after deformation at $1100{ }^{\circ} \mathrm{C}$ was lower than after deformation at $900^{\circ} \mathrm{C}$, which may be inconsistent with the finding that a high deformation temperature can promote minimal precipitation at low temperature, and could result in high hardness in ferrite [11].

The precipitates were spherical, and their chemical compositions contained Ti, Mo, and C, as showed in Fig. 3 . Fine nanometer-scale carbides with sizes below $10 \mathrm{~nm}$ were uniformly distributed in ferrite when the holding time was $60 \mathrm{~s}$, but it is noteworthy that many large carbides with sizes of approximately $20 \mathrm{~nm}$ were observed when the holding time was $1,800 \mathrm{~s}$, and several small carbides formed a cluster, resembling one large precipitate; both the clustering and coarsening of carbides would reduce the hardness.

Curved interphase precipitation was clearly visible in bright and dark field images as shown in Fig. 4a, b, and this was the main interphase precipitation morphology in these samples. All the samples showed identical behavior in that the interphase rows and sizes of interphase particles increased with the holding time as well as the random precipitation as shown in Fig. 4c, d.

However, a precipitation-free zone (PFZ) was observed near grain boundaries when the deformation temperature was $1100^{\circ} \mathrm{C}$ as shown in Fig. 4e. The austenite undergoes dynamic recrystallization when deformed at $1100{ }^{\circ} \mathrm{C}$, resulting in large austenite grains with a low dislocation density before the ferrite transformation caused by the high temperature and low cooling rate $\left(10^{\circ} \mathrm{C} \mathrm{s}^{-1}\right)$

Fig. 3 TEM micrographs showing the precipitation characteristics at $\mathbf{a} 60 \mathrm{~s}$ and $\mathbf{b} 1800 \mathrm{~s}$ for the samples deformed at $900^{\circ}$ with cooling rate of $50^{\circ} \mathrm{s}^{-1}$ after holding

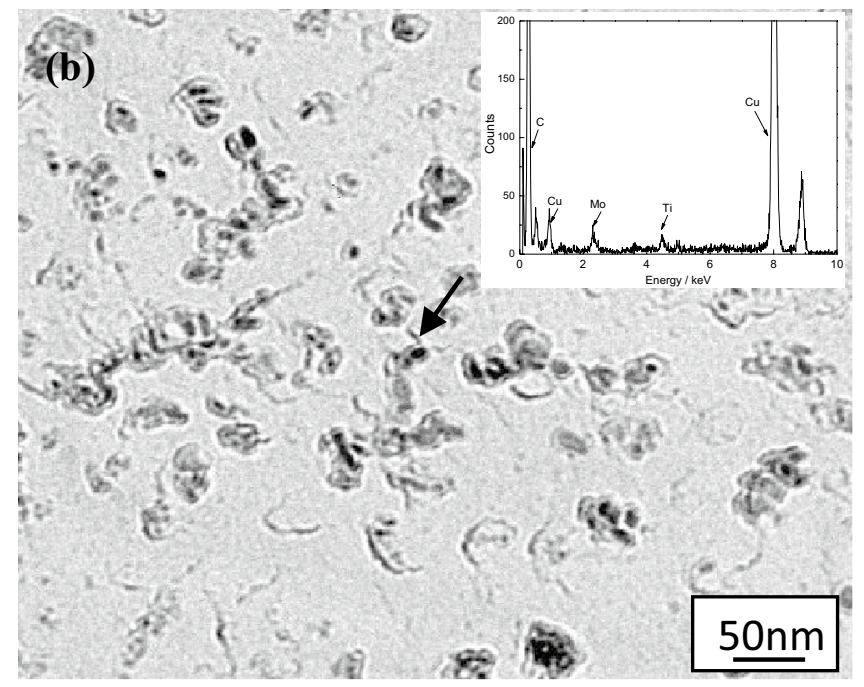



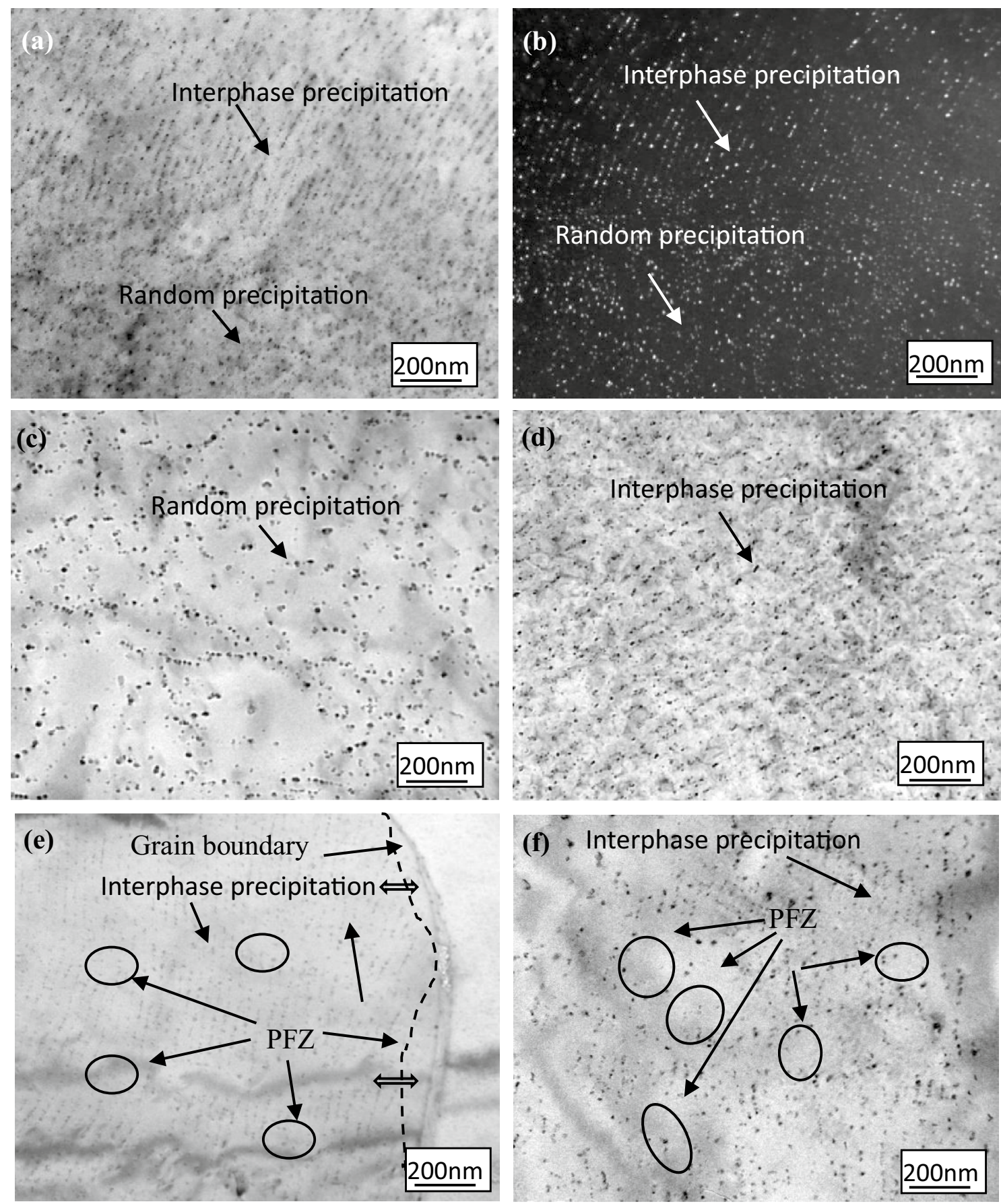

Fig. 4 TEM micrographs showing the precipitation characteristics at $\mathbf{a}, \mathbf{b} 60 \mathrm{~s}$ and $\mathbf{c}, \mathbf{b} 1800 \mathrm{~s}$ for the samples deformed at $900^{\circ}$ with $0.1^{\circ} \mathrm{s}^{-1}$ after holding, at $\mathbf{e} 60 \mathrm{~s}$ and $\mathbf{f} 1800 \mathrm{~s}$ for the for the samples deformed at $1100^{\circ}$ with $0.1^{\circ} \mathrm{s}^{-1}$ after holding

employed in this experiment. Due to the difference in carbon solubility between austenite and ferrite, a carbon-depleted zone is formed in front of the $\gamma / a$ interface according to the theories of interphase precipitation and phase transformation, and the larger austenite grains lead to a large and irregular interphase precipitate row spacing; this variation in interphase precipitation characteristics with grain size results from the formation of carbondepleted zones [12]. However, the prior austenite grain boundaries were the favored sites for precipitate coarsening, and as the precipitates coarsen, they consume solute elements around the grain boundary regions $[12,21]$. PFZs about $100 \mathrm{~nm}$ wide were observed near the grain boundaries, but these showed no obvious coarse precipitates, so 
the PFZs may be attributed to the first reason mentioned above. Due to the PFZ near the grain boundary, the hardness rapidly decreased; thus, such PFZs should be avoided because of this low hardness and potential adverse effect on the toughness due to the inhomogeneous distribution. Besides many coarse precipitates were observed after prolonged holding, PFZs were also observed inside the interphase precipitation region in addition to random precipitation (similar to Fig. 4c, not shown here) as shown in Figs. 4e, f. As regards the above analysis, the low hardness of ferrite under these conditions may be caused by low carbide density in ferrite due to PFZs near the grain boundary and within grains after short and prolonged holding times, and coarsening of carbides after prolonged holding times.

\section{Conclusions}

The precipitation hardening characteristics in Ti-Mo ferrite-containing microalloyed steel were affected by the rolling temperature and cooling rate after isothermal holding. PFZs were observed both near the grain boundary and grain interior when rolling was conducted in the recrystallization region, and the hardness of ferrite decreased because of this phenomenon. This was confirmed by both TEM observations and hardness testing. Small carbides grow or aggregate, resulting in low hardness in ferrite grains as the holding time increased, but the same hardness can be obtained at a slow cooling rate even after the same prolonged holding.

Acknowledgements This study was supported by the National Natural Science Foundation of China (NNSFC) (51674079). This work was also supported by China Postdoctoral Science Foundation (CPSF) (2016M600211).

\section{Compliance with ethical standards}

Conflict of interests The authors declared no potential conflicts of interest with respect to the research, authorship and/or publication of this article.

\section{References}

1. Funakawa Y, Shiozaki Y, Tomita K, Yamamoto T, Maeda E (2004) Development of high strength hot-rolled sheet steel consisting of ferrite and nanometer-sized carbides. ISIJ Int 44:1945-1951

2. Chen MY, Goune M, Verdier M, Brechet $Y$, Yang JR (2014) Interphase precipitation in vanadium-alloyed steel: strengthening contribution and morphological with austenite to ferrite transformation. Acta Mater 64:78-92
3. Yi HL, Xu Y, Sun MX, Liu ZY, Wang GD (2014) Influence of finishing cooling temperature and holding time on nanometer-size carbide of Nb-Ti microalloyed steel. J Iron Steel Res Int 21:433-438

4. Zhang YJ, Miyamoto G, Shinbo K, Furuhara T, Ohmura T, Suzuki T, Tsuzaki K (2015) Effects of transformation temperature on VC interphase precipitation and resultant hardness in low-carbon steels. Acta Mater 84:375-384

5. Xu Y, Zhang WN, Sun MX, Yi HL, Liu ZY (2015) The blocking effects of interphase precipitation on dislocations' movement in Ti-bearing microalloyed steels. Mater Lett 139:177-181

6. Wang N, Ji YZ, Wang YB, Wen YH, Chen LQ (2017) Two modes of grain boundary pinning by coherent precipitates. Acta Mater 135:226-232

7. Clark S, Janik V, Lan Y, Sridhar S (2017) Interphase precipitationan interfacial segregation model. ISIJ Int 57:524-532

8. Wang YQ, Clark SJ, Janik V, Heenan RK, Venero DA, Yan K, Mccartney DG, Sridhar S, Lee PD (2018) Investigating nano-preciptation in a V-containing HSLA steel using small angle neutron scattering. Acta Mater 145:84-96

9. Wang ZQ, Sun YH, Zhou YY, Yang ZG, Jiang FC (2018) Microstructure, precipitation and mechanical properties of a titaniumtungsten alloyed hot rolled high strength steel. Mater Sci Eng A 718:56-63

10. Kim YW, Hong SG, Huh YH, Lee CS (2014) Effects of rolling temperature in the precipitation hardening characteristics of Ti-Mo microalloyed hot-rolled high strength steel. Mater Sci Eng A 615:255-261

11. Kim YW, Kim JH, Hong SG, Lee CS (2014) Effects of rolling temperature on the microstructure and mechanical properties of Ti-Mo microalloyed hot-rolled high strength steel. Mater Sci Eng A 605:244-252

12. Wang JT, Hodgson PD, Bikmukhametov I, Miller MK, Timokhina I (2018) Effects of hot deformation on grain boundary precipitation and segregation in Ti-Mo microalloyed steels. Mater Des 141:48-56

13. Chen CY, Yen HW, Kao FH, Li WC, Huang CY, Yang JR, Wang SH (2009) Precipitation hardening of high strength low alloy steels by nanometer-sized carbides. Mater Sci Eng A 499:162-166

14. Chen CY, Yang JR, Chen CC, Chen SF (2016) Microstructural characterization and strengthening behavior of nanometer sized carbides in Ti-Mo microalloyed steels during continuous cooling process. Mater Charact 114:18-29

15. Poliak El, Jonas JJ (1996) A one parameter approach to determining the critical conditions for the initiation of dynamic recrystallization. Acta Mater 44:127-136

16. Poliak El, Jonas JJ (2003) Critical strain for dynamic recrystallization in variable strain rate hot deformation. ISIJ Int 43:692-700

17. Campos SS, Morales EV, Kestenbach HJ (2004) Detection of interphase precipitation in microalloyed steels by microhardness measurements. Mater Charact 52:379-384

18. Okamoto R, Borgenstam A, Agren J (2010) Interphase precipitation in niobium microalloyed steels. Acta Mater 58:4783-4790

19. Chen CY, Chen SF, Chen CC, Yang JR (2015) Control of precipitation morpholopy in the novel HSLA steel. Mater Sci Eng A 634:123-133

20. Mukherjee S, Timokhina I, Zhu C, Ringer SP, Hodgson PD (2017) Clustering and precipitation processes in a ferritic titaniummolybdenum microalloyed steel. J Alloys Compd 690:621-632

21. Wang Z, Zhang H, Guo C, Leng Z, Yang Z, Sun X, Yao C, Zhang Z, Jiang $F$ (2016) Evolution of $(\mathrm{Ti}, \mathrm{Mo}) \mathrm{C}$ particles in austenite of a Ti-Mo-bearing steel. Mater Des 109:361-366 